\title{
Diet in Saudi Arabia: findings from a nationally representative survey
}

\author{
Maziar Moradi-Lakeh ${ }^{1}$, Charbel El Bcheraoui ${ }^{1}$, Ashkan Afshin ${ }^{1}$, Farah Daoud ${ }^{1}$, \\ Mohammad A AlMazroa ${ }^{2}$, Mohammad Al Saeedi ${ }^{2}$, Mohammed Basulaiman ${ }^{2}$, \\ Ziad A Memish', Abdullah A Al Rabeeah ${ }^{2}$ and Ali H Mokdad ${ }^{1, *}$ \\ ${ }^{1}$ Institute for Health Metrics and Evaluation, University of Washington, 2301 5th Avenue, Suite 600, Seattle, \\ WA 98121, USA: ${ }^{2}$ Ministry of Health of the Kingdom of Saudi Arabia, Riyadh, Saudi Arabia
}

Submitted 30 March 2016: Final revision received 8 September 2016: Accepted 10 October 2016: First published online 15 December 2016

\begin{abstract}
Objective: No recent original studies on the pattern of diet are available for Saudi Arabia at the national level. The present study was performed to describe the consumption of foods and beverages by Saudi adults.

Design: The Saudi Health Interview Survey (SHIS) was conducted in 2013. Data were collected through interviews and anthropometric measurements were done. A diet history questionnaire was used to determine the amount of consumption for eighteen food or beverage items in a typical week.

Setting: The study was a household survey in all thirteen administrative regions of Saudi Arabia.

Subjects: Participants were 10735 individuals aged 15 years or older.

Results: Mean daily consumption was 70.9 (SE 1.3) g for fruits, 111.1 (SE 2.0) g for vegetables, 11.6 (se 0.3) g for dark fish, 13.8 (SE 0.3) $\mathrm{g}$ for other fish, 44.2 (SE 0.7) $\mathrm{g}$ for red meat, $4 \cdot 8$ (SE 0.2) $\mathrm{g}$ for processed meat, 10.9 (SE 0.3) $\mathrm{g}$ for nuts, 219.4 (SE 5.1) $\mathrm{ml}$ for milk and 115.5 (sE 2.6) $\mathrm{ml}$ for sugar-sweetened beverages. Dietary guideline recommendations were met by only $5.2 \%$ of individuals for fruits, $7.5 \%$ for vegetables, $31.4 \%$ for nuts and $44.7 \%$ for fish. The consumption of processed foods and sugar-sweetened beverages was high in young adults.

Conclusions: Only a small percentage of the Saudi population met the dietary recommendations. Programmes to improve dietary behaviours are urgently needed to reduce the current and future burden of disease. The promotion of healthy diets should target both the general population and specific high-risk groups. Regular assessments of dietary status are needed to monitor trends and inform interventions.
\end{abstract}

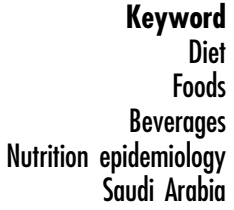

Dietary risks are among the most important risk factors globally and in the Kingdom of Saudi Arabia (KSA) in particular ${ }^{(1,2)}$. Like many other regions of the world, the nutrition transition in the Middle East has contributed to the rising burden of non-communicable diseases ${ }^{(1,3)}$. In KSA in 2013 , poor diet accounted for $10.4 \%$ (95\% CI 8.9, 12.2\%) of disability-adjusted life years and $22 \cdot 1 \%$ (95\% CI $18 \cdot 7$, $24.5 \%)$ of deaths ${ }^{(3,4)}$. FAO data show an overall increase in food supply (1961-2007) in KSA, with an increase in the supply of sugar, meat, animal fat, offal (organ meats), eggs and milk, and a levelling trend in the vegetable and fruit supply ${ }^{(5)}$. A similar trend was reported earlier in $2000^{(6)}$. Khan and $\mathrm{Al} \mathrm{Kanhal} \mathrm{reported} \mathrm{a} \mathrm{rapidly} \mathrm{increasing} \mathrm{surplus} \mathrm{of}$ energy and protein availability in KSA after 1975, compared with the recommended daily allowances ${ }^{(7)}$.
Previous reports have shown the dietary patterns or energy/nutrient intakes in specific population subgroups or regions of $\mathrm{KSA}^{(8)}$. However, nationally representative diet data from KSA are limited to food availability. Food availability data (such as FAO data) do not represent intake, as they do not account for wastage and other uses. Moreover, they do not provide information on diet by age, sex and socio-economic status.

In 2012, the KSA Ministry of Health published dietary guidelines on the amount and composition of recommended foods to promote a healthy diet among the population $^{(9)}$. However, there are not enough data on the success of the guidelines' implementation, the population's current dietary status and the potential impacts of the guidelines. Therefore, the aims of the present study 
were to describe the amount of consumption of different types of foods and beverages in KSA; to describe dietary consumption by age, sex, socio-economic status and subnational administrative regions; and to assess the degree to which Saudis' diets met the dietary guidelines.

\section{Methods}

Performed between April and June 2013, the Saudi Health Interview Survey (SHIS) was a national multistage survey of individuals aged 15 years or older. For this survey, KSA was divided into thirteen regions. Each region was divided into sub-regions and blocks. All regions were included in the survey. A probability-proportional-to-size method was used to randomly select sub-regions and blocks. Households were then randomly selected from each block. A roster of household members was conducted and an adult aged 15 years or older was randomly selected to be surveyed from each selected household. If the randomly selected adult was not present, our surveyors made an appointment to return. A total of three visits were attempted before the household was considered as a nonresponse. More details about the study are available in previous publications ${ }^{(10-13)}$.

The Saudi Ministry of Health and its institutional review board (IRB) approved the study protocol. The University of Washington IRB deemed the study IRB-exempt, since the Institute for Health Metrics and Evaluation received deidentified data for the present analysis. All respondents had the opportunity to consent and agree to participate in the study.

The survey included forty-two questions on diet (a diet history questionnaire), as well as questions on socioeconomic status (educational and household monthly income levels) and other aspects of health. Respondents were asked to report the number of days that they consumed eighteen food or beverage items in a typical week over the last year. The food and beverage items included in the survey were: fruits; pure (100\%) fruit juices; vegetables; dark meat fish; other fish; shrimp; red meat; poultry meat; processed meat (meats preserved by smoking, curing or salting, or by the addition of preservatives, such as in the case of pastrami, salami, bologna, other packaged lunch meats or deli meats, sausages, bratwursts, frankfurters and hot dogs); other processed foods (such as fast foods, canned foods, packaged entrées or packaged soup); eggs; nuts; milk; yoghurt; laban (a beverage of yoghurt mixed with salt, which is also known as ayran or doogh); labneb (strained yoghurt); cheese; and sugar-sweetened beverages (SSB). For each type of food/beverage that the respondents reported at least one day of consumption per typical week, the respondents were asked: 'How many servings of [this food/beverage] do you usually consume/eat/drink on one of those days?' The interviewers used specific pictures that represented the serving size of each type of food/beverage. Moreover, respondents were asked about the type of oil or fat most often used for meal preparation, and the usual type of dairy products (full-fat, low-fat, non-fat) and bread in the household.

There were insufficient data to calculate total energy consumption directly. Supplemental File 1 (see online supplementary material) shows the method for indirect estimation of energy intake and the energy-adjusted daily food/beverage consumption estimates. Although not an ideal method for energy adjustment, it can provide more comparability with other studies for interested readers. An energy adjustment is also necessary to compare the status with the dietary guideline recommendations.

Average numbers of daily servings - and their equivalent weight (grams) for foods, or volume (millilitres) for beverages - were calculated. In cases where the weight of a serving size had not been clarified in the survey manuals (fruits, vegetables, processed meat, processed foods and eggs), we matched our visual manual as closely as possible to phrases in the guidelines of the US Department of Agriculture to assign an average weight ${ }^{(14)}$. For fruits and vegetables, we used the weighted average weight of one serving of the most common types of fruits and vegetables based on the most recent food supply data of FAO in $\mathrm{KSA}^{(15)}$. The 99th percentiles of consumption were used as cut-off points to identify and exclude implausibly high levels of intake.

The statistical software package Stata 13.1 for Windows was used for the analyses and to account for the complex sampling design.

\section{Results}

A total of 12000 households were contacted and 10735 participants ( 5253 men and 5482 women) completed the SHIS, for a response rate of $89.4 \%$.

Table 1 demonstrates the average daily consumption of different food and beverage items. Table 2 shows the food and beverage consumption of men and women. Non-adjusted consumption of fruit, red meat, other processed foods, eggs and SSB was statistically higher in men than women, while yoghurt and cheese consumption was higher in women than men. Daily consumption of fruits and vegetables was reported by $10 \cdot 8$ (SE 0.4) \% and 25.9 (SE 0.6) \%, respectively, and 27.0 (SE 0.7)\% reported daily drinking of SSB.

Mean consumption of processed meat, other processed foods and SSB was clearly higher in younger age groups (Table 3), while laban consumption was higher in older age groups. Consumption of fruit, shrimp, labneh and cheese had an increasing pattern with higher education (Table 4). As demonstrated in Table 5, consumption of some of the food items (fruit, shrimp, red meat and labneb) was higher in individuals with higher household 
Table 1 Average daily food and beverage consumption of Saudi adults, 2013

\begin{tabular}{|c|c|c|c|c|c|c|c|c|}
\hline \multirow[b]{2}{*}{ Food/beverage item } & \multirow[b]{2}{*}{ Serving size } & \multirow[b]{2}{*}{$N$} & \multicolumn{2}{|c|}{ Weight/volume units } & \multicolumn{2}{|c|}{ Serving size } & \multicolumn{2}{|c|}{ Meet the recommendations } \\
\hline & & & Mean & SE & Mean & SE & $\%$ & SE \\
\hline Fruits $(\mathrm{g})$ & $103 g^{*}$ & 10187 & 70.9 & $1 \cdot 3$ & 0.675 & 0.013 & $5 \cdot 2 \dagger$ & 0.3 \\
\hline Vegetables $(\mathrm{g})$ & $105 \mathrm{~g}^{*}$ & 10334 & $111 \cdot 1$ & $2 \cdot 0$ & 1.078 & 0.019 & $7.5 \dagger$ & 0.4 \\
\hline Pure $(100 \%)$ fruit juices $(\mathrm{ml})$ & $125 \mathrm{ml}$ & 10066 & 31.9 & 0.8 & 0.269 & 0.007 & & \\
\hline Dark meat fish $(\mathrm{g})$ & $75 \mathrm{~g}$ & 10096 & 11.6 & 0.3 & 0.137 & 0.003 & $44.7 \ddagger$ & 0.7 \\
\hline Other fish (g) & $75 \mathrm{~g}$ & 10082 & $13 \cdot 8$ & 0.3 & 0.159 & 0.003 & & \\
\hline Shrimp (g) & $75 \mathrm{~g}$ & 9801 & 2.4 & 0.1 & 0.028 & 0.001 & & \\
\hline Red meat $(\mathrm{g})$ & $75 \mathrm{~g}$ & 10223 & 44.2 & 0.7 & 0.521 & 0.009 & $85.7 \S$ & 0.5 \\
\hline Poultry meat (g) & $75 \mathrm{~g}$ & 10336 & $103 \cdot 0$ & 1.8 & 1.304 & 0.022 & & \\
\hline Processed meat (g) & $69 \mathrm{~g}^{*}$ & 9667 & 4.8 & 0.2 & 0.070 & 0.003 & $80.2 \S$ & 0.6 \\
\hline Other processed foods $(\mathrm{g})$ & $399 \mathrm{~g}^{*}$ & 9664 & 97.5 & $2 \cdot 7$ & 0.244 & 0.007 & & \\
\hline Eggs $(g)$ & $92 \mathrm{~g}^{*}$ & 10219 & $46 \cdot 0$ & 0.7 & 0.500 & 0.007 & & \\
\hline Nuts $(\mathrm{g})$ & $40 \mathrm{~g}$ & 9768 & $10 \cdot 9$ & 0.3 & 0.274 & 0.007 & $31.4 \dagger$ & 0.7 \\
\hline Yoghurt (g) & $175 \mathrm{~g}$ & 10257 & $75 \cdot 4$ & $2 \cdot 0$ & 0.431 & 0.012 & $26 \cdot 2 \dagger$ & 0.7 \\
\hline Milk (ml) & $250 \mathrm{ml}$ & 10326 & $219 \cdot 4$ & $5 \cdot 1$ & 0.885 & 0.021 & & \\
\hline Laban (ml) & $175 \mathrm{~g}$ & 10269 & $116 \cdot 8$ & $2 \cdot 8$ & 0.667 & 0.016 & & \\
\hline Labneh (g) & $175 \mathrm{~g}$ & 9866 & 28.9 & 0.8 & 0.165 & 0.004 & & \\
\hline Cheese (g) & $50 \mathrm{~g}$ & 10113 & $43 \cdot 7$ & 0.9 & 0.874 & 0.018 & & \\
\hline SSB $(\mathrm{ml})$ & $125 \mathrm{ml}$ & 9967 & $115 \cdot 5$ & $2 \cdot 6$ & 0.924 & 0.021 & $78.6 \ddagger$ & 0.6 \\
\hline
\end{tabular}

SSB, sugar-sweetened beverages.

${ }^{\star}$ Estimated through matching of pictures in the survey manual with the descriptions of the US Department of Agriculture guideline ${ }^{(14)}$.

Reference dietary guidelines: †Dietary Guidelines for Americans ${ }^{(25)}$; $¥$ American Heart Association ${ }^{(24)}$; §American Institute for Cancer Research ${ }^{(23)}$.

Table 2 Daily food and beverage consumption of Saudi male and female adults, 2013

\begin{tabular}{|c|c|c|c|c|c|c|c|c|}
\hline \multirow[b]{3}{*}{ Food/beverage item } & \multicolumn{4}{|c|}{ Male $(N 5253)$} & \multicolumn{4}{|c|}{ Female ( $N 5482)$} \\
\hline & \multicolumn{2}{|c|}{ Weight/volume units } & \multicolumn{2}{|c|}{ Serving size } & \multicolumn{2}{|c|}{ Weight/volume units } & \multicolumn{2}{|c|}{ Serving size } \\
\hline & Mean & SE & Mean & SE & Mean & SE & Mean & SE \\
\hline Fruits $(\mathrm{g})$ & $75 \cdot 7$ & 1.9 & 0.620 & 0.016 & 65.9 & 1.9 & 0.547 & 0.017 \\
\hline Vegetables (g) & $105 \cdot 4$ & $2 \cdot 3$ & 0.904 & 0.020 & $117 \cdot 0$ & 3.3 & 1.032 & 0.034 \\
\hline Pure $(100 \%)$ fruit juices (ml) & $34 \cdot 0$ & $1 \cdot 2$ & 0.241 & 0.010 & $29 \cdot 7$ & $1 \cdot 1$ & 0.214 & 0.010 \\
\hline Dark meat fish $(\mathrm{g})$ & 11.5 & 0.4 & 0.123 & 0.005 & $11 \cdot 7$ & 0.4 & 0.123 & 0.004 \\
\hline Other fish $(\mathrm{g})$ & $14 \cdot 3$ & 0.4 & $0 \cdot 153$ & 0.005 & $13 \cdot 3$ & 0.4 & 0.144 & 0.006 \\
\hline Shrimp (g) & 2.5 & 0.1 & 0.026 & 0.002 & $2 \cdot 3$ & 0.1 & 0.023 & 0.002 \\
\hline Red meat (g) & 52.4 & $1 \cdot 2$ & 0.590 & 0.014 & $35 \cdot 7$ & 0.9 & 0.403 & 0.012 \\
\hline Poultry meat (g) & $106 \cdot 6$ & $2 \cdot 4$ & $1 \cdot 195$ & 0.027 & $99 \cdot 3$ & $2 \cdot 7$ & $1 \cdot 131$ & 0.033 \\
\hline Processed meat $(\mathrm{g})$ & $5 \cdot 0$ & 0.3 & 0.064 & 0.004 & 4.7 & 0.3 & 0.068 & 0.004 \\
\hline Other processed foods $(\mathrm{g})$ & $108 \cdot 4$ & 4.3 & 0.239 & 0.009 & $86 \cdot 0$ & 3.2 & 0.194 & 0.008 \\
\hline Eggs $(g)$ & 49.8 & 1.0 & 0.496 & 0.011 & $42 \cdot 0$ & 0.9 & 0.414 & 0.009 \\
\hline Nuts $(\mathrm{g})$ & 11.2 & 0.4 & 0.269 & 0.011 & $10 \cdot 7$ & 0.4 & 0.243 & 0.009 \\
\hline Yoghurt (g) & $67 \cdot 1$ & 1.9 & 0.349 & 0.010 & $84 \cdot 2$ & 3.6 & 0.420 & 0.020 \\
\hline Milk (ml) & 217.5 & 6.4 & 0.712 & 0.019 & 221.4 & 8.1 & 0.796 & 0.033 \\
\hline Laban (ml) & $122 \cdot 2$ & 3.9 & 0.580 & 0.017 & 111.2 & 3.9 & 0.568 & 0.023 \\
\hline Labneh (g) & 27.5 & 1.0 & 0.149 & 0.006 & 30.4 & 1.2 & 0.164 & 0.007 \\
\hline Cheese (g) & 40.5 & $1 \cdot 2$ & 0.672 & 0.016 & $47 \cdot 0$ & 1.4 & 0.779 & 0.023 \\
\hline SSB (ml) & 131.4 & $3 . \overline{5}$ & 0.972 & 0.028 & 98.8 & 3.8 & 0.699 & 0.030 \\
\hline
\end{tabular}

SSB, sugar-sweetened beverages.

incomes. Consumption of SSB was statistically higher in individuals with lower household incomes (Table 5). Fruit/beverage consumption in different administrative regions can be found in Supplemental File 2 (see online supplementary material).

Vegetable oils were the most common type of oil/fat used for preparation of food ( 84.5 (SE 0.5$) \%$ ). Olive oil and butter/margarine were reported by 5.3 (SE 0.3 ) \% and 4.8 (sE 0.3 ) \%, respectively. Most of the respondents reported use of full-fat dairy products $(77.6$ (SE 0.6$) \%$ ), followed by low-fat (15.0 (se 0.5)\%) and non-fat (1.3 (sE 0.1)\%); others had no preference. The most common type of bread was white bread (79.1 (sE 0.5)\%); brown bread and Saudispecific traditional breads were reported by $20 \cdot 1$ (sE 0.5 ) \% and 0.8 (se $0 \cdot 1) \%$, respectively, as the usual kind of bread.

\section{Discussion}

The present study is the first to describe dietary patterns in a nationally representative sample of adults in KSA. It 
showed poor dietary practices in the Kingdom. Saudis' dietary behaviours met dietary recommendations in only a small percentage of the population, especially for fruit and vegetable consumption, dairy products, nuts and fish meat. Young adults (15-24 years old) had a concerning pattern of high consumption of SSB, processed meat and other processed foods, as well as low intake of fruits and vegetables. Other studies on schoolchildren show that these unhealthy dietary behaviours start even sooner ${ }^{(16)}$. This evidence calls for a comprehensive programme to improve the dietary situation of Saudis. The programme should include all age ranges, considering the different needs and different dietary challenges of each age group.

A cluster of dietary risk factors is the leading risk factor for non-optimal health, with 11.3 million attributed deaths and 241.4 million attributed disability-adjusted life years per annum around the world ${ }^{(1)}$. The Global Burden of Diseases, Injuries, and Risk Factors (GBD) study showed that in Saudi Arabia, the average levels of consumption of fruits, vegetables, nuts, whole grains, PUFA and seafood $n-3$ fatty acids were far less than optimum, and the average levels of consumption of processed meats, red meats, total fatty acids, SSB and sodium were higher than optimal ${ }^{(3)}$.

In the report of the WHO 2005 STEPwise survey, there was limited dietary information on the consumption of fruits, vegetables and oils. During the time between the STEPwise survey and our current study (2005 to 2013), the percentage of individuals consuming at least five daily servings of fruits or vegetables increased slightly, from 5.5 to $7.3 \%{ }^{(11)}$. However, based on food supply data, fruit and vegetable availability in KSA (about $475 \mathrm{~g} / \mathrm{d}$ in 2010) ${ }^{(17)}$ is more than twice the average consumption in our study (less than $200 \mathrm{~g} / \mathrm{d}$ ). The difference might be related to using fruits as pure juices (about $32 \mathrm{ml} / \mathrm{d}$ ) or sweetened juices, as well as the higher potential of decay in fruits/ vegetables compared with other food items. Further details on consumption of fruits and vegetables by Saudi adults have been reported elsewhere ${ }^{(11)}$. Consumption of olive oil has increased from $1.7 \%$ in the Saudi STEPwise survey to $5 \cdot 3 \%^{(18)}$; since higher intake of olive oil is associated with reduced risk of all-cause mortality, cardiovascular events and stroke, this can be considered a good replacement ${ }^{(19)}$.

Although there was higher consumption of meat and SSB by men, and of vegetables by women, non-energyadjusted consumption is not directly comparable between men and women. Considering the fact that average energy consumption is usually higher in men, vegetable intake is expected to remain higher in women after energy adjustment. Some of the different patterns of food and beverage consumption between men and women may be explained by theories about the association of meat consumption with masculinity and vegetable consumption with femininity, but we do not have enough information for that assessment $^{(20-22)}$. 
Table 4 Daily food and beverage consumption of Saudi adults by educational level, 2013

\begin{tabular}{|c|c|c|c|c|c|c|}
\hline \multirow[b]{2}{*}{ Food/beverage item } & \multicolumn{2}{|c|}{ Primary or less ( $N 3286)$} & \multicolumn{2}{|c|}{ Elementary/high school ( $N$ 4780) } & \multicolumn{2}{|c|}{ College or higher $(N 2649)$} \\
\hline & Mean & SE & Mean & SE & Mean & SE \\
\hline Fruits $(\mathrm{g})$ & 64.2 & $2 \cdot 3$ & $55 \cdot 6$ & 1.7 & 74.8 & 3.0 \\
\hline Vegetables (g) & 99.6 & $4 \cdot 3$ & $96 \cdot 9$ & 3.0 & $108 \cdot 0$ & 3.9 \\
\hline Pure $(100 \%)$ fruit juices $(\mathrm{ml})$ & $22 \cdot 0$ & 1.4 & $25 \cdot 6$ & 1.2 & 35.8 & 1.6 \\
\hline Dark meat fish $(\mathrm{g})$ & $10 \cdot 3$ & 0.5 & 9.9 & $0 . \overline{4}$ & 11.9 & 0.6 \\
\hline Other fish $(g)$ & $12 \cdot 9$ & 0.7 & $12 \cdot 3$ & 0.5 & 13.3 & 0.6 \\
\hline Shrimp (g) & 0.9 & 0.1 & $2 \cdot 1$ & 0.1 & 3.6 & 0.3 \\
\hline Red meat $(\mathrm{g})$ & 43.9 & 1.6 & $42 \cdot 1$ & 1.2 & 41.5 & 1.4 \\
\hline Poultry meat (g) & 99.2 & 3.5 & 93.8 & 2.5 & 82.5 & 3.5 \\
\hline Processed meat (g) & $4 . \overline{8}$ & 0.5 & 4.2 & 0.3 & $5 \cdot 1$ & 0.4 \\
\hline Other processed foods $(\mathrm{g})$ & $66 \cdot 3$ & 4.2 & $95 \cdot 3$ & 4.0 & $92 \cdot 8$ & 4.7 \\
\hline Eggs (g) & 36.4 & 1.2 & 43.8 & 1.0 & $44 \cdot 8$ & 1.3 \\
\hline Nuts $(\mathrm{g})$ & 11.7 & 0.8 & 9.6 & 0.3 & $9 \cdot 7$ & 0.4 \\
\hline Yoghurt (g) & 74.9 & $5 \cdot 0$ & $62 \cdot 1$ & 2.4 & $69 \cdot 7$ & $4 \cdot 0$ \\
\hline Milk (ml) & $219 \cdot 6$ & 9.5 & $177 \cdot 2$ & $6 \cdot 9$ & $168 \cdot 6$ & 8.5 \\
\hline Laban (ml) & 104.5 & $4 \cdot 3$ & 97.6 & $3 \cdot 8$ & $99 \cdot 8$ & $5 \cdot 1$ \\
\hline Labneh (g) & $20 \cdot 3$ & 1.4 & 27.9 & 1.3 & 35.5 & 1.7 \\
\hline Cheese (g) & 33.0 & 1.3 & 37.3 & 1.1 & 38.9 & 1.4 \\
\hline SSB (ml) & 86.5 & $5 \cdot 1$ & $120 \cdot 9$ & 3.9 & 88.5 & $4 \cdot 3$ \\
\hline
\end{tabular}

SSB, sugar-sweetened beverages.

Table 5 Food and beverage consumption of Saudi adults by household monthly income level, 2013

\begin{tabular}{|c|c|c|c|c|c|c|}
\hline \multirow[b]{2}{*}{ Food/beverage item } & \multicolumn{2}{|c|}{ Less than 5000 Riyals (N 3161) } & \multicolumn{2}{|c|}{ 5000-14 999 Riyals ( $N 4549)$} & \multicolumn{2}{|c|}{15000 Riyals or more $(N 1131)$} \\
\hline & Mean & SE & Mean & SE & Mean & SE \\
\hline Fruits $(\mathrm{g})$ & 51.5 & $2 \cdot 0$ & $65 \cdot 2$ & 1.7 & $79 \cdot 3$ & 4.7 \\
\hline Vegetables (g) & $94 \cdot 1$ & $3 \cdot 7$ & $96 \cdot 2$ & $2 \cdot 2$ & 118.3 & $6 \cdot 6$ \\
\hline Pure $(100 \%)$ fruit juices (ml) & $20 \cdot 9$ & 1.5 & $28 \cdot 3$ & 1.4 & $40 \cdot 5$ & $2 \cdot 4$ \\
\hline Dark meat fish $(\mathrm{g})$ & $9 \cdot 8$ & 0.5 & $10 \cdot 8$ & 0.5 & $10 \cdot 6$ & 0.8 \\
\hline Other fish $(\mathrm{g})$ & $13 \cdot 3$ & 0.7 & $13 \cdot 8$ & 0.5 & $14 \cdot 0$ & 0.9 \\
\hline Shrimp (g) & 1.7 & 0.2 & $2 \cdot 3$ & 0.2 & $3 \cdot 9$ & 0.4 \\
\hline Red meat (g) & $37 \cdot 2$ & 1.5 & $42 \cdot 4$ & 1.2 & $50 \cdot 3$ & $2 \cdot 4$ \\
\hline Poultry meat (g) & $89 \cdot 3$ & $3 \cdot 3$ & $88 \cdot 6$ & $2 \cdot 1$ & $93 \cdot 3$ & $4 \cdot 3$ \\
\hline Processed meat $(\mathrm{g})$ & 3.4 & 0.4 & 4.4 & 0.3 & $5 \cdot 2$ & 0.7 \\
\hline Other processed foods (g) & $91 \cdot 0$ & $5 \cdot 3$ & $86 \cdot 8$ & $3 \cdot 7$ & $82 \cdot 7$ & $6 \cdot 6$ \\
\hline Eggs (g) & $38 \cdot 9$ & $1 \cdot 2$ & $45 \cdot 2$ & 1.0 & $42 \cdot 2$ & $1 \cdot 8$ \\
\hline Nuts (g) & $8 \cdot 1$ & 0.5 & $10 \cdot 1$ & 0.4 & $11 \cdot 2$ & 0.8 \\
\hline Yoghurt (g) & $66 \cdot 4$ & 3.4 & 64.6 & $2 \cdot 3$ & 61.9 & $4 \cdot 0$ \\
\hline Milk (ml) & 188.5 & $8 \cdot 7$ & $166 \cdot 5$ & 4.9 & $189 \cdot 4$ & $11 \cdot 1$ \\
\hline Laban (ml) & $104 \cdot 7$ & 4.9 & 99.5 & $3 \cdot 2$ & 98.7 & $5 \cdot 8$ \\
\hline Labneh (g) & $22 \cdot 7$ & 1.5 & 31.9 & 1.4 & $36 \cdot 4$ & $2 \cdot 7$ \\
\hline Cheese (g) & 37.5 & 1.8 & $36 \cdot 2$ & 0.9 & 35.9 & 1.8 \\
\hline SSB (ml) & $113 \cdot 6$ & $5 \cdot 4$ & $95 \cdot 9$ & $3 \cdot 2$ & 91.0 & $5 \cdot 6$ \\
\hline
\end{tabular}

SSB, sugar-sweetened beverages.

Compared with the recommendations of dietary guidelines $^{(9,23-25)}$, consumption of fruits, vegetables, dairy products and nuts is very low, and less than $45 \%$ of the KSA population consumes fish as recommended. On the other hand, there is considerable unnecessary consumption of processed meat and SSB compared with the recommendations ${ }^{(23,24)}$. A 2006 study in Lebanon showed that Lebanese adults consume the same amount of fish and red meat as Saudis in our study, but less poultry meat $(36 v .103 \mathrm{~g} / \mathrm{d})$ and eggs $(12 v .46 \mathrm{~g} / \mathrm{d})$, and more fruits and vegetables $(367 v .182 \mathrm{~g} / \mathrm{d})^{(26)}$.

The previously published GBD estimates for dietary risk factors in KSA were close to our estimates for red meat, processed meat and SSB. Our estimate for nuts was higher than previous GBD estimates (about $11 v .4 \mathrm{~g} / \mathrm{d}$ ) ${ }^{(3)}$.

Midhat et al. reported the consumption of different food items as part of the routine meals in the Qassim region of KSA. However, they did not report the amount (or serving sizes) of consumption. That study showed an increasing probability of routine intake of fish, vegetables, fresh fruits and barbecued meats (called a 'healthy diet') with increasing age ${ }^{(27)}$. Our findings showed that Saudis of older ages consume more fruit and vegetables, and fewer processed foods. The healthier diet seen among older individuals might be related to different factors, such as a birth cohort effect (due to the nutrition transition in the 
younger birth cohorts), the longer life of individuals with healthy diets, more frequent contacts between health careproviders and older individuals (compared with younger people), and better adherence among older individuals to dietary guidelines because of their perceived risk of disease and death.

The average consumption of fruit, vegetables and shrimp in individuals with a college or higher education was more than in other educational groups. The highest intake of milk was reported by individuals with primary or less education. Individuals with the lowest household income had the highest consumption of SSB, while consumption of fruits, vegetables and pure juices was lower than in individuals with higher income.

In our study, the highest intake of fish was in the Jizan, Aasir, Al Bahah and Makkah regions (all located in the south-western part of the country and close to the Red Sea), as well as in Riyadh (capital); the lowest consumption of fish was reported by residents of Ha'il, Al Jawf and Al Hudud ash Shamaliyah (all located in the north-western part of the country).

Although the prevalence of obesity has decreased in recent years in KSA, the current combination of high overweight/obesity prevalence ${ }^{(28)}$, sedentary lifestyle ${ }^{(10)}$ and inappropriate diet threatens the current and future health of the population.

Our study has some limitations. First, we used a diet history questionnaire that did not contain details for all types of foods and beverages. Second, our food and beverage consumption data are self-reported and subject to recall and social desirability biases. Third, our study did not include the amount of all foods and beverages (for instance, complex carbohydrates), and we were not able to directly calculate total energy expenditure. On the other hand, our study is based on a large sample size and used a standardized methodology for all its measures. It is nationally representative and has the merit of providing accurate data due to our near-real-time data quality monitoring through the whole survey period.

The Saudi Ministry of Health has initiated programmes and projects, such as the Crown Health Project ${ }^{(29,30)}$ and the Saudi dietary guidelines ${ }^{(9)}$, to alleviate the burden of risk factors of non-communicable diseases. The outcomes of these programmes need to be evaluated, so that the lessons learned from them can be used in the adjustment of current programmes and the planning and installation of new comprehensive programmes.

\section{Conclusion}

Our study showed that Saudis' diets do not follow the guidelines for healthy diets. Increased efforts to improve eating habits in KSA are needed. These efforts should promote a balanced diet according to energy intake and composition of diet. Specifically, increasing the consumption of fruits, vegetables, dairy products, nuts and fish should be targeted. Strategies are required to limit the consumption of processed foods and SSB, especially in young adults. These efforts should involve all stakeholders, including education representatives, agriculture partners, food companies and food importers. In addition, regular assessments of Saudis' dietary status are needed to monitor trends and inform interventions. Finally, political will is needed to enforce food labelling and manufacturing regulations.

\section{Acknowledgements}

Acknowledgements: The authors would like to thank Kevin O'Rourke at the Institute for Health Metrics and Evaluation for editing the manuscript. Financial support: This study was supported by a grant from the Ministry of Health of the KSA. The Ministry of Health had no role in the design, analysis or writing of this article. Conflict of interest: The study and the authors have not received any financial support from the food industries. Authorship: A.H.M. conceived and designed the study. M.B., Z.A.M., M.A.S. and M.A.A. performed the survey. C.E.B. and F.D. participated in questionnaire design and interviewers' training. M.M.-L., A.A. and A.H.M. analysed the data. M.M.-L., A.H.M., C.E.B., A.A., F.D., M.B., Z.A.M., M.A.S., M.A.A. and A.A.A.R. drafted or commented on the manuscript. A.A.A.R. supervised the study. All co-authors are responsible for the content of this article and have read and approved the final manuscript. Ethics of human subject participation: The Saudi Ministry of Health and its IRB approved the study protocol. The University of Washington IRB deemed the study IRB-exempt, since the Institute for Health Metrics and Evaluation received de-identified data for the analysis. All respondents had the opportunity to consent and agree to participate in the study.

\section{Supplementary material}

To view supplementary material for this article, please visit https://doi.org/10.1017/S1368980016003141

\section{References}

1. GBD 2013 Risk Factors Collaborators, Forouzanfar MH, Alexander L et al. (2015) Global, regional, and national comparative risk assessment of 79 behavioural, environmental and occupational, and metabolic risks or clusters of risks in 188 countries, 1990-2013: a systematic analysis for the Global Burden of Disease Study 2013. Lancet 386, $2287-2323$.

2. Memish ZA, Jaber S, Mokdad AH et al. (2014) Burden of disease, injuries, and risk factors in the Kingdom of Saudi Arabia, 1990-2010. Prev Chronic Dis 11, E169.

3. Afshin A, Micha R, Khatibzadeh S et al. (2015) The impact of dietary habits and metabolic risk factors on cardiovascular and diabetes mortality in countries of the Middle East and 
North Africa in 2010: a comparative risk assessment analysis. BMJ Open 5, e006385.

4. Institute for Health Metrics and Evaluation (2014) GBD compare visualization tool. http://ihmeuw.org/3qc9 (accessed July 2016).

5. Adam A, Osama S \& Muhammad KI (2014) Nutrition and food consumption patterns in the Kingdom of Saudi Arabia. Pak J Nutr 13, 181-190.

6. Madani KA, al-Amoudi NS \& Kumosani TA (2000) The state of nutrition in Saudi Arabia. Nutr Health 14, 17-31.

7. Khan MA \& Al Kanhal MA (1998) Dietary energy and protein requirements for Saudi Arabia: a methodological approach. East Mediterr Health J 4, 68-75.

8. Alsufiani HM, Kumosani TA, Ford D et al. (2015) Dietary patterns, nutrient intakes, and nutritional and physical activity status of Saudi older adults: a narrative review. J Aging Res Clin Pract 4, 2-11.

9. General Director of Nutrition, Ministry of Health (2012) Saudi Dietary Guideline (Healthy Diet Palm). Riyadh: Ministry of Health Publications.

10. El Bcheraoui C, Tuffaha M, Daoud F et al. (2016) On your mark, get set go: levels of physical activity in the Kingdom of Saudi Arabia, 2013. J Phys Act Health 13, 231-238.

11. El Bcheraoui C, Basulaiman M, AlMazroa M et al. (2015) Fruit and vegetable consumption among adults in Saudi Arabia, 2013. Nutr Diet Suppl 7, 41-49.

12. Moradi-Lakeh M, El Bcheraoui C, Tuffaha M et al. (2015) Tobacco consumption in the Kingdom of Saudi Arabia, 2013: findings from a national survey. BMC Public Health 15, 611 .

13. Moradi-Lakeh M, El Bcheraoui C, Tuffaha M et al. (2015) Self-rated health among Saudi adults: findings from a national survey, 2013. J Community Health 40, 920-926.

14. US Department of Agriculture, Agricultural Research Service (2014) National Nutrient Database for Standard Reference, Release 27. http://ndb.nal.usda.gov/ndb/foods (accessed July 2016).

15. Food and Agriculture Organization of the United Nations (2011) Food Balance Sheets, Saudi Arabia. http://faostat3. fao.org/download/FB/FBS/E (accessed October 2015).

16. Attia AAEM \& Farajat MA (2013) Selected dietary habits among female adolescents in Hail, Saudi Arabia. Am J Res Commun 1, 140-148.

17. Haddad LJ, Hawkes C, Achadi E et al. (2015) Global Nutrition Report 2015: Actions and Accountability to Advance Nutrition and Sustainable Development. Washington, DC: International Food Policy Research Institute.
18. Al-Hamdan NA, Kutbi A, Choudhry AJ et al. (2005) WHO STEPwise Approach to NCD Surveillance. Country-Specific Standard Report: Saudi Arabia. http://www.who.int/chp/steps/ 2005_SaudiArabia_STEPS_Report_EN.pdf?ua=1 (accessed July 2016).

19. Schwingshackl L \& Hoffmann G (2014) Monounsaturated fatty acids, olive oil and health status: a systematic review and meta-analysis of cohort studies. Lipids Health Dis 13, 154.

20. Ruby MB \& Heine SJ (2011) Meat, morals, and masculinity. Appetite 56, 447-450.

21. Vartanian LR (2015) Impression management and food intake. Current directions in research. Appetite 86, 74-80.

22. Levant RF, Parent MC, McCurdy ER et al. (2015) Moderated mediation of the relationships between masculinity ideology, outcome expectations, and energy drink use. Health Psychol 34, 1100-1106.

23. American Institute for Cancer Research (2007) Recommendations for Cancer Prevention. http://www.aicr.org/reduceyour-cancer-risk/recommendations-for-cancer-prevention/ (accessed July 2016).

24. Eckel RH, Jakicic JM, Ard JD et al. (2014) 2013 AHA/ACC guideline on lifestyle management to reduce cardiovascular risk: a report of the American College of Cardiology/ American Heart Association Task Force on Practice Guidelines. J Am Coll Cardiol 63, 2960-2984.

25. US Department of Health and Human Services \& US Department of Agriculture (2005) Dietary Guidelines for Americans, 2005. http://health.gov/dietaryguidelines/ dga2005/document/ (accessed July 2016).

26. Nasreddine L, Hwalla N, Sibai A et al. (2006) Food consumption patterns in an adult urban population in Beirut, Lebanon. Public Health Nutr 9, 194-203.

27. Midhet F, Al Mohaimeed AR \& Sharaf F (2010) Dietary practices, physical activity and health education in Qassim region of Saudi Arabia. Int J Health Sci 4, 3-10.

28. Memish ZA, El Bcheraoui C, Tuffaha M et al. (2014) Obesity and associated factors - Kingdom of Saudi Arabia, 2013. Prev Chronic Dis 11, E174.

29. Memish ZS, Abdullah AS, Saeedi MY et al. (2013) Methods and status of a comprehensive community-based intervention focusing on non-communicable diseases and the major risk factors in the Kingdom of Saudi Arabia. The Crown Health Project. Saudi Med J 34, 202-203.

30. Memish ZA, Saeedi MY, Al Madani AJ et al. (2015) Factors associated with public awareness of the Crown Health Program in the Al-Jouf Region. J Fam Community Med 22, 31-38. 